\title{
RELATÓRIO E PROJETO NA LICENCIATURA: A ESCRITA COMO POTENCIALIZAÇÃO DA EXPERIÊNCIA
}

\author{
Neide Luzia de Rezende*
}

\begin{abstract}
Resumo: Este artigo busca discutir aspectos relacionados a atividades de escrita do curso de Licenciatura, especificamente da disciplina de Metodologia do Ensino de Língua Portuguesa (MELP), na Faculdade de Educação da USP. Procura distinguir peculiaridades dos textos solicitados aos alunos no curso de Letras e no curso de Licenciatura. Neste último, sobretudo quando são textos decorrentes de atividades de estágio e de projeção da prática escolar do futuro professor de português.

Os Relatórios de Estágio, os Diários de Campo e os Projetos para a Sala de Aula são abordados na disciplina de MELP a partir de suas características discursivas, tendo em vista a dupla dimensão que apresentam: a de prática social e de prática escolar. Assim, o modo de ser desses gêneros é repensado à luz das necessidades de aprendizagem de texto e de escrita, numa perspectiva metalingüistica inerente aos textos acadêmicos - especialmente no curso de Letras, que forma especialistas em Língua Portuguesa-, mas são também, na Licenciatura, instrumentos da formação do profissional, no caso, formação do futuro professor de Português. Desse modo, o conhecimento acumulado é confrontado com a vivência empírica, com uma situação específica observada elou vivenciada na escola, ou ainda com uma projeção dessa experiência mediante a escrita.
\end{abstract}

Palavras-chave: Escrita - Licenciatura - Letras - Relatório - Projeto Diário de Campo - Formação de Professores

\section{Introdução}

Pretende-se abordar neste artigo aspectos da disciplina de Metodologia do Ensino de Língua Portuguesa e do estágio a ela correspondente, sediados no curso de Licenciatura da Faculdade de Educação da USP, por intermédio de atividades como o relatório e o projeto para a sala de aula. Essas práticas, mais do que dar conta de uma experiência passada (no caso do relatório) e de planejar uma experiência futura (no caso do projeto), permitem refletir sobre a formação do licenciando a partir não só dos recursos teóricos e metodológicos adquiridos na licenciatura, do contato às vezes fugaz com a escola durante o estágio, como da experiência acadêmica do licenciando.

Transformados respectivamente em gênero acadêmico (na licenciatura) e em gênero escolar (nas escolas de educação infantil e ensino básico), o relatório e o projeto

Professora de Metodologia do Ensino de Língua Portuguesa da Faculdade de Educação da USP. 
podem ser potencializados como objetos de reflexão e ir além de um mero exercício técnico, resistindo ao simplismo e à banalização que sofrem quando se tornam atividades "obrigatórias". Esses gêneros, quando produzidos na universidade, podem significar a possibilidade de se refletir - já que uma dimensão inerente à escrita nos cursos de Letras é a metalingüística - sobre essas modalidades (aliás, há quem defenda que toda escrita é metalingüística, ou seja, ajuda a refletir sobre a própria linguagem, uma vez que é preciso fazer escolhas no interior da língua ${ }^{1}$ ).

O trabalho pedagógico por meio de projetos tem se tornado cada vez mais impositivo na escola. E acho que se pode ter em relação a essa obrigatoriedade e diretivismo a mesma preocupação que António Nóvoa (1992) manifestou a respeito da perspectiva autobiográfica na formação de professores: a vigência atual do trabalho com projetos é ao mesmo tempo um sucesso e uma derrota; sucesso porque possibilita novas perspectivas de trabalho e uma mudança nas metodologias de ensino, mas derrota porque esse sucesso só é possível à custa de uma banalização do rigor metodológico e das suas dimensões críticas.

\section{Atividades de escrita como exercício acadêmico}

Antes de mais nada, cumpre destacar que textos escritos no âmbito da universidade servem primordialmente como exercícios acadêmicos - atenho-me à área de Letras -, portanto, possuem, ao mesmo tempo, uma dimensão de ensino e de aprendizagem. Nesse sentido, são instrumentos utilizados para a formação do aluno, futuro bacharel e/ou licenciado em língua portuguesa: desse nível de ensino se espera uma formação que vá além da mera instrumentalização técnica; releva a capacidade do aluno de criar conceitos, refletir sobre a tradição, apropriar-se dos conhecimentos acumulados e, quando preciso, subverter essa tradição.

Os textos escritos constituem, por um lado, um produto desse ângulo acadêmico que acabamos de expor; na escrita se encontra a possibilidade de o aluno de Letras explicitar, de diferentes modos, a sua relação com o conhecimento, basicamente verbal, que a ele é proposto. Por outro lado, os textos são instrumentos também da formação do profissional: no caso da licenciatura, trata-se da formação do futuro professor de português; portanto, a escrita guarda um necessário vínculo com a prática da sala de aula. Nesse sentido, o conhecimento acumulado é confrontado com a vivência empírica, com uma situação específica observada e/ou vivenciada na escola. Há, na licenciatura (à diferença do que ocorre em Letras), um movimento para fora do texto, quando o aluno deve escrever não mais apenas comentando ou refletindo sobre o que leu, mas associando o que leu com o que viu ou vivenciou. Ou seja, na licenciatura, do aluno se

1 "Minha visão acerca da escrita é ser ela, por sua própria natureza, uma atividade metalingüística. (...) o sistema de escrita que registra, e a partir daí representa aspectos da estrutura lingüística. Incluem-se nele as distinções entre sons, representados por letras; entre palavras, representadas por espaços; entre orações, representadas pela pontuação; entre elementos temáticos, representados pela topicalização, nas frases ou nos parágrafos; entre tipos de discurso, representados pelos gêneros.” ( Olson, 1995, p. 277-8). 
exige uma construção de texto que dê conta, por escrito, da interpretação de uma realidade experienciada; para usar uma noção paulofreireana, uma "leitura de mundo", a partir das leituras de textos que fez na vida acadêmica.

A escrita na licenciatura representa um novo desafio para o aluno proveniente do bacharelado ao ter de fazer um exercício de interpretação do observável direto, para o qual muitas vezes não tem uma resposta verbal prévia; já não pode apenas escolher entre um autor e outro, dependendo, portanto, de sua própria capacidade de reunir conhecimentos provenientes de diferentes formações discursivas para entender e explicar um dado observável.

Em suma, na licenciatura a escrita funciona, simultaneamente, como um elemento de formação do aluno, como um instrumento para avaliar sua competência na escrita, bem como sua capacidade de elaborar adequadamente um texto tendo em vista sua finalidade, e como um elemento de formação do professor, do profissional, desafiando-o a transpor por escrito a experiência vivida e a projetá-la no exercício da profissão. Evidentemente, esses dois tipos de instrumento estão fortemente associados e, se aqui os distinguimos, é para tornar mais expressivo e visível esse trabalho com a escrita no curso de licenciatura.

Contudo, as finalidades supostas nesses trabalhos são perpassadas pelo fato de serem textos produzidos na universidade, portanto são atividades escritas essencialmente voltadas para a reflexão e a crítica, se adotarmos a perspectiva da tendência crítica de que fala Bosi em "Culturas brasileiras" (1992). Quando solicitamos a confecção de um relatório ou de um projeto, há que se considerar esse espaço de produção: esses gêneros não se configuram como reprodução de modelos prontos, não são peças técnicas, não mantêm um compromisso de fidelidade ao real, ao contrário, podem livremente transfigurá-lo, desde que essa transfiguração contribua para o maior conhecimento desse real.

Tal exercício acadêmico é realizado com um pé nas práticas sociais, quer dizer, no modo como tais gêneros se configuram e funcionam fora da instituição acadêmica (sua finalidade, que deve considerar público-alvo, intenção, meios de divulgação, estrutura, assunto), acrescentando-se a esses aspectos uma dimensão metalingüística, que supõe também uma dimensão ética: o gênero solicitado na escola (e sobremaneira no ensino superior) deve ajudar a transpor do modo mais adequado possível os conteúdos e a reflexão que convencionalmente se fazem no interior dele. Trata-se de buscar - arrisco aqui uma expressão controversa - "modelos ideais", formas virtualmente mais pertinentes de construção daquele conhecimento, embora se saiba que quando transpostos para a prática social extraescolar podem sofrer alterações significativas para se adequar às situações reais ${ }^{2}$.

2 Costumamos dizer que a boa literatura, no seu trabalho de representação do mundo, faz com que, por meio da invenção, o que é essencial na realidade venha à tona, ou seja, o essencial se torna aparente, e um meio de reflexão sobre a realidade. Ora, de certo modo, é o que se faz quando se elabora, por exemplo, um projeto em sala de aula, ou quando montamos um seminário ou ainda quando o professor do ensino básico realiza um debate em classe - questão que será adiante discutida mais detidamente. 


\section{Peculiaridades do aluno da licenciatura}

Um problema que observamos em parte dos alunos de Letras que vêm para a licenciatura na faculdade de Educação é a crença numa formação voltada para um real estrito, ou melhor, para uma conformação ao real. Já ouvi de alunos na sala de aula que aqui incorremos num "abstracionismo revolucionário", ao propor a elaboração de projetos não voltados para uma "aplicação" imediata (também professores da escola básica menosprezam os projetos quando estes não passaram pela "prova" da sala de aula, considerando-os exemplos de como a universidade está "distante da realidade" da escola pública).

Em palestra na Faculdade de Educação ${ }^{3}$, o professor Franklin Leopoldo e Silva, da Faculdade de Filosofia da USP, lembrou que há hoje uma tendência a considerar a formação escolar como introjeção coletiva de uma mentalidade em que a informação está voltada para o adestramento de habilidades para o status quo. Há sempre uma expectativa, em cursos de formação promovidos pela universidade e também nos cursos de licenciatura, de que a universidade venha em socorro da prática, oferecendo soluções para os problemas que ocorrem na escola, algo parecido com "o mundo do receituário" que Alfredo Bosi denunciava há cerca de três décadas: "O que se transmite aos alunos do ginásio (e aqui atingimos o cerne da dinâmica educacional), o que se estratifica em termos de instrução fundamental, é, quase sempre, a fórmula final, reduzida, reificada, da antepenúltima tendência da cultura superior" (1992, p.317).

É compreensível que se espere da universidade ajuda para os anseios de professores, para os problemas às vezes graves que os profissionais da educação enfrentam; entretanto, essa solução não é direta nem imediata, uma vez que esses problemas, circunstanciais na sua maioria, decorrem de outros mais profundos, e são estes que devem ser investigados, de modo a que cada um busque se situar e se entender no âmago dessas estruturas. Isso aparece efetivamente na Faculdade de Educação, que, desde sua separação da Faculdade de Filosofia, acabou como um campo de "ciências aplicadas", às vezes tendendo a responder a demandas imediatistas da escola.

\section{O estagiário e a licenciatura}

O estagiário se encontra numa posição privilegiada em relação à sala de aula e à teoria (pode observar à distância e ministrar aula numa posição de aprendiz, pode trazer as questões observadas e vivenciadas para a faculdade e discuti-las com colegas e professores), mas algumas variáveis fazem com ele tenha dificuldade em reconhecer esse valor.

3 Mesa-redonda: "A formação inicial do professor de filosofia", dia 26.09. IV Semana de Educação da FEUSP, de 25 a 29 de setembro de 2006, composta ainda por Silvio Gallo e Celso Favaretto. 
No caso da USP, em que o curso de licenciatura é de responsabilidade da faculdade de Educação e de regra procurado na etapa final do bacharelado ${ }^{4}$, há um generalizado menosprezo pelas questões da Educação, a qual, associada à educação básica, acaba sendo considerada como depositária de um saber menor se comparado ao saber universitário. Desde que adquiriu sua autonomia em relação à faculdade de filosofia, sua celula mater, a pedagogia é considerada de segunda categoria. Além disso, a obrigatoriedade da licenciatura para o aluno exercer o ofício de professor produz uma má-vontade e um rechaço fortes, uma vez que o aluno ao entrar na universidade e escolher uma área de conhecimento, no caso da faculdade de Letras, em geral não inclui a licenciatura, considerada, por essas e outras razões, de qualidade inferior quando comparada às unidades de origem do aluno. Assim, no semestre inicial da licenciatura também há por parte dos docentes o trabalho de lutar contra essa imagem negativa e tentar dissolver as resistências em relação ao curso.

Ao mesmo tempo, o licenciando sente uma grande insegurança em relação à sua própria capacidade de ser professor, uma vez que no confronto com a escola pública durante o estágio não consegue acionar direito o conteúdo que recebeu da universidade e que, na maior parte das vezes, sente não ter internalizado bem, não ter aprendido como deveria; percebe esse conteúdo de modo fragmentado, e ainda não vê bem as vinculações entre as disciplinas que teve ao longo do bacharelado. Encontra-se, na escola, durante o estágio, diante de uma "cultura escolar" que já foi a sua, mas que ficou distante, pois na universidade (pelo menos na pública) esses conteúdos não são retomados 5 .

É comum o aluno na licenciatura criticar o curso de Letras por não lhe ter ensinado a gramática normativa que, ainda crê, seja o conteúdo "natural" da escola. Aliás, esse é um dos pontos de resistência do aluno no início da disciplina de Metodologia do Ensino de Língua Portuguesa da FEUSP. Em nossa concepção, a gramática normativa e classificatória não deve ser o conteúdo predominante do ensino de português na escola básica, pois trabalhamos com uma outra concepção de ensino de língua portuguesa, mas o licenciando desconfia dessas nossas perspectivas adotadas para o ensino de língua materna, talvez vendo nelas mais um "abstracionismo revolucionário", uma vez que não são elas que sustentam o programa dos professores com quem estagia. Ao contrário, lá na escola básica, ele observa o esforço do professor para inculcar em seus alunos uma dimensão metalingüística da língua por meio das regras e nomenclaturas da gramática normativa e dos exercícios de fixação. Ora, ele mesmo, o estagiário, percebe que não domina aquele conteúdo, que aprendeu mal ou não aprendeu quando estava na escola. Então, cobra-se esse conhecimento - e cobra-o da universidade, de certo modo solidarizando-se com o professor da escola, condoendose de sua dificuldade de "ensinar" para alunos indisciplinados e "analfabetos" - mas há também, em outro pólo, estagiários que imputam a dificuldade de aprender ao professor, visto muitas vezes como sem preparo e como insensível aos problemas dos alunos.

\footnotetext{
$4 \quad$ Atualmente, na licenciatura da FEUSP, o licenciando tem uma carga de 180 horas de estágio: sendo 120 horas na disciplina de Metodologia, ao longo dos dois semestres. A USP inicia neste ano de 2006 um processo de adaptação às exigências de 400 horas de estágio propostas pelo CNE . Na FEUSP, o aluno deverá cumprir 300 horas, sendo as outras 100 de responsabilidade da sua unidade de origem.

Muitas instituições particulares de ensino superior, ao contrário, têm oferecido cursos de redação e de gramática, a exemplo do que faz o ensino médio, para suprir, segundo elas, necessidades urgentes dos alunos em relação ao português padrão.
} 
Ou seja, ao mesmo tempo em que menospreza a escola pública, o licenciando parece ter medo dela. Sem contar que muitas vezes também chega na Licenciatura com uma escrita deficitária, com problemas de texto e de gramática que já não se esperam nem se aceitam de aluno nesse estágio de formação ${ }^{1}$ - ao contrário, acredita-se que, finalizando os estudos de graduação, ele seja capaz de escrever textos complexos e dominar plenamente a norma culta.

Ora, talvez seja nesse espaço desprestigiado da licenciatura que pela primeira vez ele vai se sentir desafiado a exercitar um outro tipo de escrita, a buscar solução para um problema que não é dado pelo texto, mas que deverá se equacionar pela escrita, uma vez que o licenciando deverá apresentar o seu relatório ou projeto no curso em decorrência do estágio realizado. Ele é desafiado a utilizar o conhecimento que recebeu verbalmente para responder a determinada situação. E é no ato da escrita do relatório e do projeto (gêneros supostamente comuns à licenciatura) que esse desafio é revelado, quando então parece que teoria e prática se encontram.

\section{O relatório de estágio e o diário de campo}

Os gêneros acadêmicos funcionalizados nos cursos de formação docente muitas vezes têm suas fronteiras apagadas e uma coisa se transforma em outra, como, de resto, ocorre em geral entre os gêneros. Ora, as diferentes conformações discursivas, que chamamos aqui de gêneros do discurso, numa perspectiva bakhtiniana, orientam para modos diferentes de apreensão do mundo, os quais podem ser exemplificados com o relatório e o diário de campo. Ainda que esses dois gêneros sejam úteis para a formação docente, cumprem funções diferentes.

O diário é um registro, por mais crítico que possa ser, das observações e das ocorrências do dia-a-dia; por força do próprio gênero, é fragmentado, ao sabor das idas e vindas do cotidiano escolar e da subjetividade do observador: apresenta insights, lampejos e percepções registradas junto com as descrições das cenas escolares cotidianas e das notações objetivas e dos dados. A rigor, o diário como gênero não permite distanciamento entre o enunciado e a enunciação, quer dizer, as observações por escrito do autor vêm marcadas pelo sentimento do imediato, às vezes por uma sensação efêmera captada num momento e que pode perdurar ou não como objeto de posterior reflexão. O diário não aspira a nenhuma unidade, ou melhor, a unidade é dada ao longo das páginas, na lógica da alternância e descontinuidade, que não se impõe a resolver as contradições que porventura aparecem (Gusdorf, 1991).

\footnotetext{
$1 \quad \mathrm{Na}$ análise lingüística que empreendeu de 23 relatórios de concluintes de licenciatura em Letras de universidades públicas de cinco regiões do país, Maria das Graças S. Rodrigues (2002) identificou variadas dificuldades de escrita nos textos desses alunos, o que a levou a afirmar: "A dificuldade de produzir textos escritos é tão presente nas licenciaturas em Letras que quando o egresso chega à pósgraduação tem como maior barreira a produção escrita de seus próprios trabalhos, porque essa lacuna não foi resolvida na licenciatura". (Rodrigues, 2002, v. 1, p. 145)
} 
Estudando diários de professores, Mary Louise Holly (2000) observou o seu processo de escrita num curso de formação, percebendo que nesse gênero as questões surgem, são momentaneamente esquecidas, mas depois pode-se voltar a elas, na tentativa de respondê-las.

"Escrever sobre estes processos [as observaçãoes e questões no percurso profissional] pode abrandar a sua progressão e conservá-los como se fossem instantâneos que nos permitem reunir e explorar seqüências narrativas que, de outro modo, se perderiam numa miríade de outros pensamentos, ações e acontecimentos." (p. 101)

Visto assim, como um processo, o diário pode ser um material de extrema riqueza para a confecção do relatório, que vai, justamente, se servir tanto das notações objetivas quanto daquelas mais subjetivas que podem dar lugar a reflexões então articuladas ao campo do conhecimento no qual se insere a tarefa do aluno-estagiário.

O relatório, que, no nosso caso, deve ser entregue ao final de cada semestre letivo (na licenciatura da FEUSP, as metodologias têm dois semestres) vai, portanto, se apropriar do diário de campo, e ganha em relação a este uma maior unidade, garantida pelas leituras, discussões e reflexões feitas ao longo do semestre e pela própria imposição do gênero relatório. Nesse momento, é hora de reunir os conhecimentos teóricos, metodológicos e práticos, é o momento de expor, como escreveu uma aluna, “o confronto de idéias, com a realidade, a relativização da teoria, as dificuldades da relação do professor, dos alunos, do conteúdo, das metodologias etc." 2 . Elaborado com o distanciamento no tempo e com a mediação da escrita, reconstrói pela palavra o contexto e pode revê-lo criticamente. Segundo W. Ong, "O distanciamento que a escrita realiza desenvolve um novo tipo de exatidão na verbalização, tirando-a do contexto existencialmente rico, mas caótico, de muitas das enunciações orais" (1998, p. 120).

Há, pois, um distanciamento propiciado pelo tempo, mas também pela particularidade do gênero, que supõe a síntese, refletida e objetiva, da experiência tida, de modo a documentar um trabalho realizado ${ }^{3}$. Essa é certamente uma experiência única para o estagiário, não só porque talvez seja o primeiro relatório que possivelmente escreveu na vida - já que o gênero não é comum nas disciplinas de Letras $^{4}-$, mas porque resulta de uma experiência vivenciada, quando, até então, salvo alguma atividade excepcional (projeto de iniciação científica, por exemplo, ou mestrado ou doutorado), o seu trabalho de escrita foi essencialmente intertextual, ou seja, seus textos

\footnotetext{
2 São palavras de minha orientanda de Doutorado, monitora pelo PAE-CAPES no primeiro semestre de 2006, quando mestranda, Gabriela Rodella de Oliveira.

Algumas variações de estilo são possíveis, mas a estrutura é menos maleável, pois tem de narrar o trabalho realizado. Um bom exemplo são os relatórios que Graciliano Ramos apresentou em 1929 e 1930 ao governador de Alagoas, para dar conta de sua gestão na prefeitura de Palmeira dos Índios. Manteve as partes necessárias, mas arejou o quadro com uma linguagem mais irreverente, com comparações inteligentes e bem-humoradas, sem nunca, contudo, perder a objetividade. (Graciliano Ramos, Viventes das Alagoas. Rio de Janeiro/São Paulo: Record, 1980).

$4 \quad$ Maria das Graças S. Rodrigues (cf. nota 5) sugere na sua tese a escrita orientada de vários gêneros discursivos nos cursos universitários: "com certeza uma ênfase nos gêneros acadêmicos seria relevante: assim, o relatório de estágio, por exemplo, não seria o primeiro relatório escrito pelo concluinte" (2002, p. 144)
} 
tinham como matéria outros textos, que traziam a experiência de um outro indivíduo transformada ou potencializada pela escrita.

O relatório na licenciatura tem um caráter de comprovação, de documentação, que remete à experiência concreta e particular daquele que escreve, portanto, nesse sentido, reveste-se de uma importância especial (se, de fato, o aluno atribuir valor a esse trabalho). O relatório revê a experiência tida em retrospectiva a partir de um determinado ponto de sua formação e é nessa hora que, dentro dessas condições, o ato apurado, cuidadoso e consciente de escrever pode se constituir num importante elemento de aprendizagem, uma vez que a experiência, em si, só parcialmente garante o saber - "o pensamento nasce através das palavras", afirma Vigotsky (1998).

E esse pensamento já vem orientado pela opção do texto: como diz Bakhtin, quando aprendemos a falar, aprendemos não só uma organização sintática, mas também uma organização textual. Ou seja, temos não só uma gramática implícita, mas uma gramática textual definida pela discursividade. Por isso, ao discorrer sobre o ato da escrita em si, não podemos esquecer de que esse ato não existe sem estar inserido numa situação comunicacional, que será expressa por uma determinada organização do discurso, social e historicamente definida. Por exemplo, com relação ao diário e ao relatório, o caráter do ato se modifica se for um ou outro: no diário, a falta de distanciamento entre enunciado e enunciação, o registro rápido do fenômeno ocorrido requer uma escrita de certo modo "instantânea", à qual não se retorna, estando mais próxima da oralidade e de um gênero primário, sem elaboração da escrita e do pensamento. No relatório, ao contrário, há uma formação complexa, que permite uma elaboração lingüística mais lenta e consciente.

Bruner e Weisser escrevem que:

$\mathrm{O}$ ato do auto-registro, como observaram todos os autobiógrafos ponderados desde Sto. Agostinho, separa o ser que está contando do ser passado ou dos "seres" sobre os quais se está contando. Segundo Benveniste, o "eu" que fala ou escreve vive na "instância do discurso" onde tenta personificar um ser criado a partir da memória. (1995, p. 144, grifos e aspas do autor)

Assim, a obrigatória mudança que a perspectiva adotada para o fato experimentado sofre no tempo ainda é redimensionada a partir de outras variantes, como quando o estagiário apresenta na sala de aula de Metodologia um episódio marcante, o qual é discutido pelos colegas e pelo professor. Nesse processo, outros elementos aparecem para que ele possa reavaliar o ocorrido e revê-lo sob nova perspectiva, o que corrobora a afirmação de Bruner e Weisser (1995, p. 144), ao pensarmos no relatório: "O narrador e seu objeto 'compartilham o mesmo nome, mas não o mesmo tempo e espaço"”.

Em geral, nas turmas sob minha responsabilidade, é feita uma seleção dos relatórios que irão compor uma espécie de banco de relatórios, dele sendo excluídos: aqueles mal escritos, cuja leitura pode representar um constrangimento para seu autor; aqueles nos quais é possível identificar fraude, ou seja, o estágio não foi realizado e o aluno inventou um relatório (em geral a inventio é pobre e repleta de preconceitos e 
lugares-comuns); aqueles nos quais não se percebe funcionalização da bibliografia do curso nem das concepções que foram discutidas, apenas aparecendo uma visão banalizada da escola e do professor ${ }^{5}$. Os relatórios mais bem acabados (assim como os projetos) podem ser publicados na Revista $M E L P^{6}$. Esses relatórios têm sido fonte de pesquisa para alunos de pós-graduação da USP e da PUC-SP.

\section{Projeto: a dupla dimensão}

O trabalho com projetos tem sido uma constante no sistema escolar atual. Mas, a exemplo do que disse há mais de dez anos Hernández (1996), um de seus teóricos mais importantes, parece ter-se tornado uma fórmula, uma receita, não um heurístico, desprovido da carnadura que um projeto requer para ser potencializado: a "pedagogia de projetos" em voga hoje na área educacional, como forma de organizar o conteúdo a ensinar, ao ser transformado em fórmula, já não é capaz de propiciar o conhecimento. Em geral, o que se chama de projeto na escola é um esquema de projeto, em que se enunciam o tema, os objetivos, a justificativa, o cronograma, uma bibliografia, tudo organizado em uma, duas, três páginas no máximo, como se o "como fazer" fosse dominado por todos. É claro que é possível encontrar projetos fortes, bem feitos, bem orientados, com elaboração e condução realizadas com responsabilidade pelos profissionais na escola, mas estes constituem a exceção, não a regra. Em razão disso, a "moda" de projetos tornou-se malvista e para estes torcem o nariz aqueles que já consideram "pedagogos" e "pedagogia" cientistas e ciência de importância menor.

Enquanto o relatório tem como objeto algo realizado, o projeto deve se referir a uma experiência imaginada, e isso representa um primeiro obstáculo para a sua elaboração na licenciatura. Como o professor e o licenciando não estão efetivamente desenvolvendo um trabalho real com os alunos na escola, ou seja, não estão inseridos de fato no universo escolar e cientes do andamento e da rotina, o projeto parece tecer, pois, uma "abstração revolucionária". De todo modo, é fundamental que o aluno tenha conhecimento sobre a escola básica (imagina-se um conjunto de referências formado por aquilo que ele guarda do passado, pelo que conhece do presente, pelas representações de escola que construiu e pelas quais se pauta, bem como ter para si uma concepção de língua e de seu ensino).

\footnotetext{
5 Maria da Graça S. Rodrigues (2002) observa que, nos relatórios analisados para a sua pesquisa, ainda que alguns cursos contem com um manual para a confecção do relatório, há ausências que dificultam o bom acabamento do gênero em questão:"Os relatórios segmentados são heterogêneos quanto às seções que o constituem, há relatórios que não contêm a seção de introdução e outros que não contêm a de conclusão". Problemas encontrados pela autora nos 23 relatórios analisados: omissão de elementos paratextuais (instituição, emissor, receptor e ano de produção); falta da seção de abertura e explicitação da proposta do texto; omissão das seções que integram o relatório; falta de conclusão; ocorrência de repetições que poderiam ter sido evitadas; dificuldades de efetivação da concordância verbal e concordância nominal; ruptura da continuidade de sentido (dados colhidos da p. 139 à 143).

Revista eletrônica da disciplina, semestral, cujo primeiro número saiu em setembro de 2006. http://www2.fe.usp.br/ lalec/revistamelp/numeros/
} 
Ao elaborarmos um projeto para a escola nas aulas de Metodologia do Ensino de Língua Portuguesa, é importante levar em consideração os elementos a seguir elencados.

\subsection{Uma concepção de projeto.}

Particularmente nas minhas disciplinas de MELP, a concepção de projeto para a escola é adotada de Hernández (1996), quer dizer, os alunos lêem o texto dele e o discutimos em sala, buscando adaptá-lo para o exercício escolar que estamos propondo. Em essência, o projeto, como proposto pelo autor espanhol, deve responder a uma necessidade da escola e a um interesse do professor, e todos - alunos e professores aprendem; suas etapas podem ser revistas, planejando-se o conteúdo no tempo e antecipando-se os obstáculos; o percurso por um tema-problema favorece a análise, buscando-se estabelecer relação entre a escola e o que acontece fora dela.

\subsection{Relação do projeto com a disciplina}

O projeto é, antes de tudo, um trabalho acadêmico, ou seja, trata-se de um instrumento de ensino e aprendizagem, portanto, deve responder - e talvez mais do que qualquer outro gênero na universidade, por suas características - àquela dupla dimensão: responder a uma prática social e a uma prática escolar. Então é necessário verificar a que princípio vamos vincular a concepção de Hernández. A que interesse da disciplina o projeto responde? Em primeiro lugar, na concepção do autor espanhol, o projeto é interdisciplinar, deve ser fruto de um trabalho em equipe e de responsabilidade da escola. Ora, ele se torna, na disciplina de Metodologia, um projeto de língua portuguesa, portanto espoliado de sua natureza interdisciplinar (se se considerar interdisciplinar aqui a inter-relação de disciplinas escolares); contudo, propomo-nos manter uma perspectiva interdisciplinar para que se preserve a essência dessa concepção de projeto, procurando estabelecer uma intrínseca relação entre os diferentes domínios do conhecimento e não uma relação exterior com as disciplinas escolares. Assim, ainda que reduzido a uma disciplina, ele guarda a interdisciplinaridade in nuce, o que permite uma abertura para questões mais amplas, suscitadas durante $o$ desenvolvimento do trabalho.

\subsection{Um ideal de projeto}

Os estagiários de língua portuguesa raramente, pela situação do estágio no nosso contexto, têm a oportunidade de colocar em prática qualquer projeto realizado na Faculdade de Educação. O que fazem (e o que lhes é proposto) é observar e ouvir as necessidades apresentadas pelo professor da disciplina na escola, observar o perfil dos 
alunos e também suas dificuldades na matéria, além de buscar desenvolver um projeto que responda àquelas necessidades em parte reais, em parte supostas ${ }^{7}$.

Ao propormos o desenvolvimento em grupo de um projeto, é evidente que as intenções devem ser compartilhadas e as idéias negociadas para que se transformem num tema comum. Quer dizer, aquelas necessidades que os estagiários identificaram, associadas a interesses deles por determinados temas, frutos de discussão no grupo, vão constituir um projeto, que decerto não é real (e aqui retomo minhas reflexões do começo), no sentido de se ater estritamente a determinada situação de determinada escola e de procurar dar uma resposta didática a isso; trata-se de partir dessa realidade como uma espécie de situação-síntese dos problemas que podem ser observados em outras situações escolares, distanciar-se por meio da reflexão e da investigação capazes de revelar aspectos do real que muitas vezes não aparecem quando o observamos muito de perto e estamos mergulhados no universo em questão. Com base no vivido e observável, projeta-se uma realidade, da qual se procura imaginar, de certo modo ficcionalizando, os obstáculos, os problemas e suas possíveis resoluções. Trabalha-se com uma representação de escola e de projeto - o que de resto faz-se sempre, ainda que se acredite "retratar" a realidade escolar.

Ao se propor a elaboração de um projeto para a sala de aula, busca-se um "ideal de projeto" tanto em relação a sua composição quanto a seu conteúdo. Ou seja, que ele tenha do ponto de vista de sua estruturação, de sua organização formal interna, uma extensão e profundidade que permitam visualizar um possível desenvolvimento, em suas diferentes partes (apresentação do tema, pressupostos teóricos e metodológicos, justificativa, objetivos, seqüência didática, mecanismos de avaliação...). No cotidiano escolar essa possibilidade - ou potencialidade - de desenvolvimento e previsão dos obstáculos acaba sendo difícil de ocorrer, uma vez que o tempo se transforma num obstáculo quase intransponível, devido à sobrecarga de trabalho que possuem os professores.

Dessa forma, escrever esses gêneros na universidade pressupõe resgatar esse tempo que a tarefa requer e pensar o trabalho à luz das teorias mobilizadas e das críticas levantadas, buscando repensar os problemas e propor soluções que não aparecem ainda ou aparecem de forma simplificada na prática cotidiana do professor, em geral desgastado pelo excesso de trabalho e desprovido do tempo necessário à reflexão e à mudança.

\subsection{Aproveitar o ritmo da cultura universitária}

\footnotetext{
7 “Os relatos factuais também expressam uma intenção orientada para a audiência, e a crítica de tais relatos exige que reconheçamos tal intenção. Não é uma tarefa fácil: até mesmo os alunos altamente capacitados se equivocam, tomando afirmativas escritas como a expressão direta de fatos objetivos, em vez da expressão de crenças de quem escreve. Só no séc. XX, e depois de acumular uma considerável experiência de escrever e ler, percebemos que os relatos são asserções e que os fatos dependem da teoria." (Olson, 1997, p. 286)
} 
A reflexão e a crítica têm um ritmo próprio; ir e voltar sobre o mesmo objeto, buscando vê-lo sob ângulos diferentes, exige tempo. O ato reflexivo e o crítico estão intimamente associados ao trabalho da escrita - como diz Walter Ong, a escrita permite que se estude. Há um tempo exigido pelo trabalho de leitura e um outro ainda maior exigido pela elaboração escrita. $\mathrm{Na}$ escola, parece já não haver esse tempo distendido que o estudo requer. $\mathrm{Na}$ fala dos professores, revela-se a ansiedade com a falta de tempo para tudo: cuidar da casa, dos filhos, do cônjuge, de tempo para ler, para preparar aulas, para fazer reuniões pedagógicas (muitas vezes o horário reservado a estas se transformam num surrupiado momento de descontração, quando se queixam dos alunos, da própria escola, se trocam receitas, se comercializam diferentes tipos de produto etc.). A escola não encontra tempo para realizar os seus projetos, só pode fazê-lo no ritmo que adotou, por isso não é de surpreender que o resultado sejam os esquemas desvitalizados, a falta de pesquisa e a dificuldade de escrita por parte dos professores. Por isso, realizar espécies de "projetos ideais" no curso de licenciatura é um modo de se oferecer à atividade o tempo que ela requer e que a universidade pode, em princípio, conceder, ainda que abstratamente.

\subsection{Uma combinação da perspectiva de gênero e de projeto}

Combinar os gêneros propicia um trânsito entre a escola e a sociedade. Contudo, aparecem temas de outra ordem que são igualmente redirecionados para essa perspectiva: é importante que haja no projeto a possibilidade de observar, na escola, por meio da língua, o funcionamento das práticas sociais. Como diz Bakhtin, os discursos respondem às variadas esferas das atividades presentes na sociedade.

Pode-se mobilizar diferentes gêneros discursivos, relativamente estáveis, de modo a serem reconhecidos e apropriados para a comunicação cotidiana. Permite, ademais, a elaboração de seqüências didáticas interessantes, nas quais se incluem atividades de leitura, de escrita, de análise lingüística, de saídas da escola para visitas a lugares de estudo, convites a profissionais de diferentes áreas, escritores etc.

\subsection{Ter como perspectiva um destinatário para o trabalho}

Ter em vista um leitor/interlocutor é essencial para direcionar o trabalho. Mais do que ser "aplicado" é importante que os autores dos projetos saibam que poderão ser lidos e que seus textos poderão gerar reflexões e outros textos. Como diz Umberto Eco, todo escritor, quando escreve, tem em mente um leitor, empírico ou virtual, e é para essa interlocução que o discurso se modaliza linguisticamente. No caso dos projetos, sua circulação e divulgação indicam quem será esse leitor: 1. os projetos mais bem acabados circularão entre os alunos do ano seguinte e poderão fecundar outros projetos (uma idéia parcial ou integralmente retomada em projeto diferente; uma proposta secundária que se torna principal; um aprofundamento do projeto original etc.); 2 . uma seleção mais estrita dos projetos para inclusão revista da disciplina, onde poderá ser lido 
sobretudo por professores; 3. possibilidade de apresentação dos projetos nas sessões de comunicação tanto dos Seminários de Metodologia do Ensino de Língua Portuguesa, quanto da Semana de Educação, na FEUSP, que reúnem licenciandos, pedagogos e muitos professores da rede pública e particular.

\section{Conclusão}

Para concluir, gostaria de enfatizar que a escrita desses trabalhos leva à articulação da pesquisa e da prática na licenciatura, sendo essa prática uma representação da aula de língua portuguesa: busca-se recuperar uma natureza do projeto que tem desaparecido da escola, uma vez que o trabalho escolar promove um achatamento dos seus objetos, reduzindo-os a uma estrutura elementar e descarnada. Busca-se então no projeto realizado em sala de aula recuperar um modelo de projeto capaz de tornar mais aprofundado e efetivo o trabalho, modelo que, sob riscos, denominou-se "ideal de projeto".

É de se destacar também que, para compreendermos a nós próprios e ao mundo, a escrita é uma das ferramentas mais poderosas, que ela propicia um distanciamento do objeto que está presente na nossa consciência; ela nos permite olhar para ele e buscar compreendê-lo. É isso o que se pretende com a confecção do relatório e do projeto: articular as experiências do estagiário por meio da escrita e atribuir-lhes sentido.

\section{Referências bibliográficas}

BOSI, Alfredo. "Cultura brasileira e culturas brasileiras". In: colonização. São Paulo: Companhia das Letras, 1992.

. Dialética da

BRUNER, J., WEISSER, S., “A invenção do ser: a autobiografia e suas formas”. In: OLSON, D. R., TORRANCE, N. Cultura escrita e oralidade. São Paulo: Ática, 1995.

GUSDORF, Georges. Les écritures du moi. Paris: Odile Jacob, 1991.

HERNÁNDEZ, Fernando. "Os projetos de trabalho e a necessidade de mudança na educação e na função da escola". In: Porto Alegre: Artes Médicas, 1996. - Transgressão e mudança da educação.

MELP - Revista de Metodologia do ensino de Língua Portuguesa, n. 1-4, 2006-9.

NÓVOA, António (org.). Vidas de professores. Porto: Porto Editora, 1992. 
OLSON, David. "A escrita e a formação da mente". In: O mundo no papel. São Paulo, Ática, 1997 (Col. Múltiplas Escritas).

. "A escrita como atividade metalingüística". In: OLSON, D. R., TORRANCE, N. Cultura escrita e oralidade. São Paulo: Ática, 1995.

OLSON, D. R., TORRANCE, N. Cultura escrita e oralidade. São Paulo: Ática, 1995.

ONG, W. Oralidade e cultura escrita: a tecnologização da palavra. Trad. Enid Abreu Dobranzky. Campinas: Papirus, 1998.

RODRIGUES, Maria das Graças Soares. A organização do relatório de Prática de Ensino de Língua Portuguesa. Um perfil textual do concluinte de Letras. Tese de Doutoramento. UFPE. Centro de Artes e Comunicação. Programa de Pós-Graduação em Letras e Lingüística, 2002.

SCHNEUWLY, B. "Os gêneros escolares. Das práticas de linguagem aos objetos de ensino", Revista Brasileira de Educação, n. 11, mai./jun.ago 1999, p.5-15.

VIGOTSKI, L. S. Pensamento e palavra. In: Paulo: Martins Fontes, 1998. . Pensamento e linguagem. São

\begin{abstract}
This article aims at discussing some aspects related to writing activities from a Teacher Education course, specifically in the subject Metodologia do Ensino de Lingua Portuguesa (MELP - Portuguese Teaching Methodology), which is taught at Faculdade de Educação (USP). It seeks to distinguish some peculiarities found in those texts assigned to Language and Literature and Teacher Education students. In the latter group, especially when texts result from training activities and upcoming Portuguese teachers' practice projection.

Probation Reports, Field Journals and Class projects are addressed in the MELP course from their discursive features, aiming their two different dimensions: social and school practices. So, the main characteristics of those genres are revisited in light of learning and writing needs, in a metalinguistic perspective that is inherent to scholarly literature - especially in Language and Literature courses, which train specialists in Portuguese - but are also instruments to professional training of Portuguese teachers-to-be. Thus, the accumulated knowledge is confronted with empirical experience, from a specific situation observed and / or experienced in school, or with a projection of that particular experience through writing.
\end{abstract}

Keywords: Writing - Teacher Training Course - Letters - Report - Project Field Journal - Teaching Training Course 